\title{
Lack of relationship between PTEN 32-bp and TP53 16-bp Ins/Del polymorphisms and chronic hepatitis $B$ virus infection
}

\author{
Ebrahim Eskandari $^{1,2}$ - Tayebeh Dahmardeh ${ }^{3}$. Fatemeh Dahmardeh ${ }^{4}$. \\ Elham Pahlevani ${ }^{5} \cdot$ Malihe Metanat $^{5}$
}

Received: 5 April 2017/Accepted: 8 August 2017/Published online: 22 August 2017

(C) Indian Virological Society 2017

\begin{abstract}
TP53 and phosphate and tension homolog (PTEN) are two tumor suppressor genes that regulate cell proliferation, migration, and death. P53 and PTEN deficiency has been associated with hepatic fibrosis, a prominent pathological feature associated with chronic hepatitis $\mathrm{B}$ (CHB). The present study is aimed to assess the association of PTEN 32-bp Ins/Del (rs34421660) and TP53 16-bp Ins/Del polymorphisms with CHB infection susceptibility. A total of 411 subjects were recruited in this case-control study of 213 patients with CHB infection and 198 healthy individuals as controls. PTEN and TP53 deletions were detected by polymerase chain reaction method. We found no significant association between PTEN 32-bp Ins/Del polymorphism and the risk for CHB using either of codominant (Ins/Del vs. Ins/Ins: $P=0.427$; Del/Del vs. Ins/Ins: $P=0.235)$, dominant (Ins/Del + Del/
\end{abstract}

Electronic supplementary material The online version of this article (doi:10.1007/s13337-017-0391-7) contains supplementary material, which is available to authorized users.

Elham Pahlevani

elham_pahlavani@yahoo.com

1 Genetic of Non-Communicable Disease Research Center, Zahedan University of Medical Sciences, Zahedan, Islamic Republic of Iran

2 Department of Clinical Biochemistry, School of Medicine, Zahedan University of Medical Sciences, Zahedan, Islamic Republic of Iran

3 Department of Biology, Faculty of Sciences, Ferdowsi University of Mashhad, Mashhad, Islamic Republic of Iran

4 Biology Department, School of Science, Zabol University, Zabol, Islamic Republic of Iran

5 Infectious Diseases and Tropical Medicine Research Center, Zahedan University of Medical Sciences, Zabol, Islamic Republic of Iran
Del vs. Ins/Ins $P=0.343$ ) or recessive genetic model (Del/ Del vs. Ins/Ins + Ins/Del: $P=0.516$ ). At allelic level although the PTEN Del variant allele was more common in CHB patients compared to controls (55 vs. 51), but the difference did not reach the statistical significant range (OR $0.87, P=0.327)$. Similarly, no association was observed between TP53 16-bp Ins/Del and the risk for CHB infection at both genotype and allele levels $(P>0.05)$. In summary, our study demonstrated that the PTEN 32-bp and TP53 16-bp Ins/Del polymorphisms did not affect the risk of CHB infection in the Iranian population.

Keywords Chronic hepatitis B · Ins/Del polymorphism . PTEN · TP53

\section{Introduction}

Hepatitis B virus (HBV) infection is the most prevalent cause of acute and chronic hepatitis as well as chronic infection worldwide, and it is related with the occurrence of liver malignancy [6]. It is a global health concern and in addition to acute, fulminant or chronic hepatitis, it may also result in liver cirrhosis and liver carcinoma [4]. HBV is a DNA virus which infects over 400 million people globally, in particular in Asia Pacific region which includes $75 \%$ of those infected with $\operatorname{HBV}[19,31]$. Over $90 \%$ of adult onset HBV infections are treated within 6 months, while the remaining $5-10 \%$ develop persistent infection, which is known as chronic hepatitis B (CHB) [19]. Up to $40 \%$ of these CHB patients will develop cirrhosis, liver failure, or hepatocellular carcinoma (HCC) [29]. In United States, HBV infection is also responsible for annually 4000-5500 deaths [8]. Two important factors are associated with the HBV development including 
host immunological factors [32] as well as genetic factors [7].

Phosphatase and tensin homologue deleted on chromosome 10 (PTEN) is one of the commonest targeted tumor suppressor genes in human cancers, encoding a 403-residues dual specificity phosphatase with both lipid and protein phosphatase activities [21, 30]. The PTEN gene produces a lipid phosphatase that acts as a negative regulator of the Phosphatidylinositol-3-kinase (PI3K) signaling pathway for cell development and propagation. PTEN deregulation plays a significant role in a spectrum of metabolic disorders related to hepato-carcinogenesis [20]. Growing evidence has demonstrated that hepatic PTEN expression/activity is changed in hepatic disorders resulting in deregulation of the (PI3K)/AKT pathway, which subsequently leads to development of hepatic-associated disorders such as non-alcoholic fatty liver disease (NAFLD), non-alcoholic steatohepatitis (NASH) [24], alcoholic liver disease (ALD) [27], HBV [5], HCV [2] and HCC [24, 25]. Horie et al. [15] have shown that hepatocyte-specific PTEN-knockdown (PTEN KO) mice undergo steatohepatitis with ballooned hepatocytes and hepatic fibrosis which may lead to HCC.

The PTEN gene is located on human chromosome $10 q 23.3 .3,4$ [30], and spans for $200 \mathrm{~kb}$. It consists of 9 exons and 8 introns, and encodes the PTEN protein composed of 403 amino acid residues [28]. PTEN gene includes a 32-bp deletion polymorphism (rs34421660) mapped on intron 2, but its function in human diseases is still unclear. A few studies have examined the correlation between the PTEN 32-bp deletion variant and liver-related diseases [3, 10]. Ding et al. [9] evaluated the association between this genetic variation and the risk for HCC in a Chinese population [9]. Besides, Hashemi et al. [13] have investigated the relationship between this variation and metabolic syndrome (MeS) in an Iranian population but they found no relationship between 32-bp deletion variant and $\mathrm{MeS}$.

The p53 is a tumor suppressor gene and responsible for cell cycle regulation and protection of genomic stability, and its malfunction has been implicated with multistage hepatocarcinogenesis. The TP53 16-bp IVS3 (rs17878362) is a duplication polymorphism located on intron 3 of the gene, and its Insertion variant has been related with reduced production of p53 transcript and altered p53 mRNA processing, proposing that this variation might be a risk factor for human malignancies [11]. The gene polymorphisms in P53 gene such as codon 72 Arg/Pro polymorphism has been shown to be associated with the risk of hepatocellular carcinoma (HCC) [16], but no study has been performed with respect to the TP53 16-bp polymorphism in hepatic-related diseases. In our previous study [11], we showed that TP53 16-bp duplication polymorphism was a risk factor for breast cancer (BC) in codominant, dominant and allelic comparisons in a population from Zahedan, the city our subjects for this study were collected from.

There is growing evidence for the PTEN and P53 functions and their signaling pathways in hepatopathogenesis. Both genes also involve a deletion polymorphism that its function is not well characterized in populationbased studies. So we performed the present study to identify the function of TP53 16-bp and PTEN 32-bp deletion polymorphisms on the risk for chronic HBV infection in an Iranian population.

\section{Materials and methods}

\section{Study population}

The current case-control study included 215 chronic HBV patients and 202 healthy subjects as the control group. Patients with CHB were recruited from Bou-Ali hospital, Zahedan, Iran during 2013-2015, and their ethnicity was Sistani, Baluch or others. The main exclusion criteria included were human immunodeficiency virus (HIV) or HCV co infection, or having any verification of clinically related hepatic disorder inluding evident auto-immune hepatitis-primary biliary cirrhosis, HCC, previous history of alcohol abuse or previous liver transplantation. Multiple liver biochemistry measurements were performed such as alanine aminotransferase (ALT), aspartate aminotransferase (AST) and alkaline phosphatase (ALP). Patient were separated into two groups based on their HBV DNA loads [22]. Group 1 included patients with low serum HBV DNA levels ( $<2000 \mathrm{IU} / \mathrm{mL} ; \mathrm{n}=63)$, and group 2 comprised of patients with high titers of HBV DNA $(\geq 2000 \mathrm{IU} / \mathrm{mL}$; $\mathrm{n}=34)$.

The control group included healthy blood donors who were adjusted for age, sex, and geographic area, and all had normal liver performance and no history of former liver disease, and were negative for HBV and HCV. The study got the approval of the ethics committee of Zahedan University of Medical Sciences, Zahedan, Iran and all patients gave informed consent to participate in this study.

\section{Viral assessment}

Hepatitis B surface antigen (HBsAg) was tested using a commercial kit (Enzygnost, Germany) while HBV-DNA in HBV-positive patients was extracted and tested by polymerase chain reaction (PCR), (Cinagen, Iran). HCV antibodies were tested by using a commercial kit (Enzygnost, Germany). All patients were positive for $\mathrm{HBsAg}$, HBVDNA, and negative for $\mathrm{HCV}$ antibodies. The liver 
biochemistry measurements were performed for alanine aminotransferase (ALT), aspartate aminotransferase (AST) and alkaline phosphatase (ALP).

\section{Genotyping of PTEN 32-bp and TP53 16-bp Ins/Del polymorphisms}

Blood samples were collected by taking $5 \mathrm{~mL}$ venous blood into sterile EDTA-containing tubes from all individuals involved in this study. We used Salting-out method for DNA isolation as explained previously [12].

In Brief, we transferred $500 \mu \mathrm{L}$ of each blood sample into a $1.5-\mathrm{mL}$ microfuge tube and added $1 \mathrm{~mL}$ cell lysis buffer (10 mM Tris-HCl, $11 \% \mathrm{w} / \mathrm{v}$ sucrose, $5 \mathrm{mM} \mathrm{MgCl} 2$, and $11 \% \mathrm{v} / \mathrm{v}$ Triton X-100). Microfuge tubes were gently mixed and centrifuged for $2 \mathrm{~min}$ at $6000 \mathrm{rpm}$ at room temperature and then the supernatant was removed. The process was repeated twice. Next, $300 \mu \mathrm{L}$ buffer II (10 mM Tris- $\mathrm{HCl}, 10 \mathrm{mM}$ EDTA, and $10 \mathrm{mM}$ sodium citrate) and $40 \mu \mathrm{L} 10 \%$ SDS were added, and the mixture incubated for $2 \mathrm{~min}$ at room temperature. Then, $100 \mu \mathrm{L}$ saturated $\mathrm{NaCl}$ and $600 \mu \mathrm{L}$ chloroform were gently mixing, and the mixture was centrifuged for $2 \mathrm{~min}$ at $6000 \mathrm{rpm}$. The Supernatant was transferred to a new microfuge tube, where $700 \mu \mathrm{L}$ cold isopropanol was added, followed by gentle mixing and centrifugation for $1 \mathrm{~min}$ at $12,000 \mathrm{rpm}$ for $2 \mathrm{~min}$ at $4{ }^{\circ} \mathrm{C}$. The supernatant was discarded and $700 \mu \mathrm{L}$ cold $70 \%$ ethanol was added. The suspension was gently mixed and centrifuged for $1 \mathrm{~min}$ at $12,000 \mathrm{rpm}$ at $4{ }^{\circ} \mathrm{C}$. Pellets were subsequently dried before dissolving in $100 \mu \mathrm{L}$ distilled water. The DNA quality was examined by electrophoresis on $1 \%$ agarose gel, quantitated spectrophotometrically and preserved at $-20{ }^{\circ} \mathrm{C}$ till future application.

The PTEN 32-bp deletion polymorphism was genotyped by using a combination of forward and reverse primers $\left(5^{\prime}-\right.$ CCAGCCCTCACTAAAA ACAAA- $3^{\prime}$ and $5^{\prime}$-CAAGT GTCCAAGCAGCAAA- $3^{\prime}$, respectively) as described previously [13]. Polymerase chain reaction (PCR) was done by routine PCR Mastermix (Genetbio, Denmark) based on the manufacturer's advised procedure. The Cycling conditions were $95^{\circ} \mathrm{C}$ for $5 \mathrm{~min}$, followed by 30 cycles at $95{ }^{\circ} \mathrm{C}$ for $30 \mathrm{~s}, 60{ }^{\circ} \mathrm{C}$ for $30 \mathrm{~s}$ and $72{ }^{\circ} \mathrm{C}$ for $23 \mathrm{~s}$ with an ultimate extension at $72{ }^{\circ} \mathrm{C}$ for $10 \mathrm{~min}$. Each reaction was confirmed on a $2 \%$ agarose gel. The PCR products for insertion and deletion alleles included 241 and $209 \mathrm{bp}$, respectively.

The TP53 16-bp Ins/Del polymorphism was detected by PCR and applying forward and reverse primers as described previously [11]. The cycling conditions were as follows: a primary denaturation step at $95{ }^{\circ} \mathrm{C}$ for $6 \mathrm{~min}$, followed by 30 cycles at $95^{\circ} \mathrm{C}$ for $30 \mathrm{~s}, 69.5^{\circ} \mathrm{C}$ for $40 \mathrm{~s}$, and $72{ }^{\circ} \mathrm{C}$ for $30 \mathrm{~s}$ with a final extension at $72{ }^{\circ} \mathrm{C}$ for
10 min. The PCR products were revealed on $3 \%$ agarose gel involving $0.5 \mu \mathrm{g} / \mathrm{ml}$ ethidium bromide and were observed under the UV light. The TP53 wild type allele, DEL allele (no duplication) produced $119 \mathrm{bp}$ fragment and the variant alleles, designated INS allele (with $16 \mathrm{bp}$ duplication) resulted in $135 \mathrm{bp}$ fragment. We re-genotyped random samples to confirm the precision of our genotyping method, and found no disparity.

\section{Statistical analysis}

We used SPSS software Windows, version 18.0 (SPSS Inc, Chicago IL, USA) for performing statistical analyses. The relationship among TP53 and PTEN genotypes and CHB was assessed by computing the odds ratio (OR) and $95 \%$ confidence intervals $(95 \% \mathrm{CI})$ from logistic regression analyses. $P$ values below 0.05 were considered statistically significant.

\section{Results and discussion}

\section{Patients characteristics}

Demographic characteristics of CHB Patients and control group is presented in supplementary Table 1 . There was no significant difference between case and control group regarding the age, sex and the ethnicity. The PTEN 32-bp and TP53 16-bp deletion polymorphisms were effectively genotyped in 215 chronic HBV patients and 202 control subjects. The genotype and allele frequencies of the PTEN 32-bp and TP53 16-bp deletion polymorphism in the studied groups was shown in Table 1.

\section{The PTEN 32-bp Ins/Del polymorphism was not related to the risk of CHB infection}

The PTEN 32-bp deletion polymorphism was not associated with the risk of $\mathrm{CHB}$ infection. In the codominant model, the mutant homozygote genotype (Del/Del vs. Ins/ Ins) was more frequently present in CHB patients than in controls (31 vs. $27 \%$ ), but it was not associated with the risk for CHB infection (OR 0.134, 95\% CI 0.78-2.31, $P=0.239$ ). Similarly, in the dominant model the Ins/ Del + Del/Del genotype versus Ins/Ins did not affect the risk for CHB (OR 1.27; 95\% CI 0.97-2.02; $P$ value $=0.324)$. In the recessive model, the Del/Del versus Ins/Ins + Ins/Del genotype was not also associated with susceptibility to CHB in our population (OR 1.16, 95\% CI 0.76-1.78, $P=0.516$ ). At allelic level, the PTEN variant allele Del was more prevalent in HBV patients compared with controls (55 vs. 51 ), but the difference did not reach the statistical significant range (OR $0.87,95 \%$ CI $0.66-1.13, P=0.327$ ). 
Table 1 Distribution of PTEN 32-bp and TP53 16-bp Ins/Del genotypes between patients with hepatitis B infection and healthy subjects

\begin{tabular}{|c|c|c|c|c|c|c|c|}
\hline $\begin{array}{l}\text { Genetic } \\
\text { Models }\end{array}$ & Genotypes & $\begin{array}{l}\text { CHB } \\
\mathrm{N}(\%)\end{array}$ & $\begin{array}{l}\text { Control } \\
\mathrm{N}(\%)\end{array}$ & Crude OR (95\% CI) & $P$ value & *Adjusted OR $(95 \% \mathrm{CI})$ & $* P$ value \\
\hline \multicolumn{8}{|c|}{ PTEN 32-bp Ins/Del } \\
\hline \multirow[t]{3}{*}{ Codominant } & Ins/Ins & $43(20.2)$ & $48(24.2)$ & Ref. & - & Ref. & - \\
\hline & Ins/Del & $104(48.8)$ & $95(48.0)$ & $1.22(0.74-2.01)$ & 0.429 & $1.26(0.71-2.25)$ & 0.427 \\
\hline & Del/Del & $66(31.0)$ & $55(27.8)$ & $1.34(0.78-2.31)$ & 0.293 & $1.45(0.78-2.73)$ & 0.235 \\
\hline \multirow[t]{2}{*}{ Dominant } & Ins/Ins & $43(20.2)$ & $48(24.2)$ & Ref. & - & & \\
\hline & Ins/Del + Del/Del & $170(79.8)$ & $150(75.8)$ & $1.27(0.79-2.02)$ & 0.343 & $1.22(0.72-2.12)$ & 0.324 \\
\hline \multirow[t]{2}{*}{ Recessive } & Ins/Ins + Ins/Del & $147(69.0)$ & $143(72.2)$ & Ref. & - & Ref. & - \\
\hline & Del/Del & $66(31.0)$ & $55(27.8)$ & $1.16(0.76-1.78)$ & 0.516 & $1.19(0.81-1.82)$ & 0.512 \\
\hline \multirow[t]{2}{*}{ Allele } & Ins & $190(44.6)$ & $191(48.2)$ & Ref. & - & - & - \\
\hline & Del & $236(55.4)$ & $205(51.8)$ & $0.87(0.66-1.13)$ & 0.327 & - & - \\
\hline \multicolumn{8}{|c|}{ TP53 16-bp Ins/Del } \\
\hline \multirow[t]{3}{*}{ Codominant } & Del/Del & $93(43.3)$ & $89(44.1)$ & Ref. & - & Ref. & - \\
\hline & Del/Ins & 79 (36.7) & $79(39.1)$ & $1.21(0.71-2.07)$ & 0.485 & $1.18(0.65-2.31)$ & 0.481 \\
\hline & Ins/Ins & $43(20.0)$ & $34(16.8)$ & $0.96(0.63-1.47)$ & 0.840 & $0.99(0.62-1.69)$ & 0.952 \\
\hline \multirow[t]{2}{*}{ Dominant } & Del/Del & $93(43.3)$ & $89(44.1)$ & Ref. & - & Ref. & - \\
\hline & Del/Ins + Ins/Ins & $122(66.7)$ & $113(65.9)$ & $0.96(0.62-1.47)$ & 0.913 & $0.91(0.58-1.32)$ & 0.924 \\
\hline \multirow[t]{2}{*}{ Recessive } & $\mathrm{Del} / \mathrm{Ins}+\mathrm{Del} / \mathrm{Del}$ & $172(80.0)$ & $168(83.2)$ & Ref. & - & Ref. & - \\
\hline & Ins/Ins & $43(20.0)$ & $34(16.8)$ & $1.23(0.75-2.03)$ & 0.449 & $1.28(0.76-2.13)$ & 0.438 \\
\hline \multirow[t]{2}{*}{ Allele } & Del & 265 (61.6) & $257(63.6)$ & Ref. & - & - & - \\
\hline & Ins & $165(38.4)$ & $147(36.4)$ & $1.08(0.82-1.44)$ & 0.567 & - & - \\
\hline
\end{tabular}

* Adjusted for age and sex

Our findings regarding 32-bp Ins/Del variation in the PTEN gene were in accordance with the results of a few studies on HCC and MeS. Ding et al. [9] identified no association between this polymorphism and the risk of HCC in a Chinese population [9]. Likewise, Hashemi et al. [13] have found no association between this variation and $\mathrm{MeS}$ in an Iranian population.

Up now, no study has studied the functional impact of 32-bp Ins/Del (rs34421660) variation on PTEN expression/ activity. Since the rs34421660 is sited within intronic region of PTEN gene and close to its splicing regulatory site, it is assumed that it may interfere with splicing leading to inadvertent exon skipping or intron retention and affecting the activity of PTEN [9]. However, data from our study demonstrated that this intronic genetic variation was not associated with the susceptibility to HBV.

The genomic DNA of HBV contains four partly overlapping open reading frames: surface antigen, core antigen, polymerase, and $\mathrm{X}$ protein. Among the four proteins that deriving from the HBV genome, the HBx gene encodes a $17-\mathrm{kDa}$ protein that coordinates the balance between proliferation and programmed cell death, by inducing or blocking apoptosis [17]. HBx down-regulates PTEN expression and triggers unrestrained Akt activation in Chang liver cells, thus increasing the invasive potential of these cells $[5,6]$. Previous literature suggested that PTEN is involved in $\mathrm{HBV} / \mathrm{HCV}$-associated hepatocyte dysfunction [25], and that defective PTEN expression/activity is associated with the progression of several hepatic-related disorders, i.e. liver cancer [21], MeS, steatosis, steatohepatitis, fibrosis [26], cirrhosis, viral infection and cancer [25].

\section{TP53 16-bp Ins/Del variant had no effect on the risk of CHB infection}

With respect to TP53 16-bp Ins/Del, our study demonstrated lack of any association between this Ins/del polymorphism and the risk for $\mathrm{CHB}$ at both allele and genotype levels. According to our findings, the Ins/Ins genotype was not associated with $\mathrm{CHB}$ risk using codominant $(P=0.840)$ or recessive models $(P=0.449)$. Similarly, at allele level, the Ins versus Del allele did not affect the risk for CHB $(P=0.567)$. Our results supports the previous studies performed on prostate cancer [14]. Mah et al. [23], in contrast, have indicated that serum codon 249 p53 mutation is uncommon among Taiwanese patients with chronic hepatitis $\mathrm{B}$ or $\mathrm{C}$, but they found a relationship between TP53 codon 72 polymorphisms and hepatitis B 
Table 2 The prevalence of PTEN32-bp and TP53 16-bp Ins/Del Ins/Del genotypes and ethnicity in two groups of patients with high and low HBV DNA

\begin{tabular}{|c|c|c|c|}
\hline Parameter & $\begin{array}{l}\text { Patients with high HBV DNA levels } \\
\text { (>2000 MU/ML) } \\
\mathrm{N}(\%)\end{array}$ & $\begin{array}{l}\text { Patients with low } \\
\text { HBV DNA levels }(<2000 \text { MU/ML) } \\
\text { N }(\%)\end{array}$ & $P$ value \\
\hline \multicolumn{4}{|l|}{ PTEN32-bp Ins/Del } \\
\hline Ins/Ins & $9(27)$ & $23(37)$ & Ref. \\
\hline Ins/Del & $18(53)$ & $28(44)$ & 0.469 \\
\hline Del/Del & $7(21)$ & $12(19)$ & 0.546 \\
\hline \multicolumn{4}{|l|}{ TP53 16-bp Ins/Del } \\
\hline Del/Del & $18(51)$ & $29(46)$ & Ref. \\
\hline Del/Ins & $9(26)$ & $22(35)$ & 0.470 \\
\hline Ins/Ins & $8(23)$ & $12(19)$ & 0.998 \\
\hline Ethnicity (Sistani/Baluch/Others) & 12/15/18\{Mah, 2011 \#512\} & $22 / 16 / 25$ & 0.607 \\
\hline
\end{tabular}

carriers compared to patients with liver cirrhosis, HCC, or hepatitis $\mathrm{C}$ infection, which highlights the impact of $\mathrm{p} 53$ polymorphisms on $\mathrm{HBV}$ infection at primary stage of disease [23].

Table 2 shows the frequencies of PTEN 32-bp and TP53 16-bp Ins/Del Ins/Del genotypes and patients' ethnicity among two groups of CHB patients (patients with high and low HBV DNA levels). The results indicated lack of any association among PTEN or TP53 genotypes and the levels of HBV DNA $(P>0.05)$. We also compared the frequency distribution of PTEN32-bp and TP53 16-bp Ins/Del genotypes between CHB patients with high HBV DNA (>2000 MU/ML) and healthy subjects, but we found no significant association at both genotype and allele levels $(P>0.05)$. We also assessed the level of hepatic enzymes (ALT, AST, and ALP) in HBV patients with different PTEN or TP53 genotypes. The ANOVA analysis (Tukey Test) of the genotypes indicated no significant difference between the levels of hepatic enzymes (ALT, AST, and ALP) for PTEN or TP53 genotypes $(P>0.05)$ (data not shown).

One of the crucial steps in virus life cycle is their ability to modulate host defenses that favor virus propagation [2]. Chronic HBV infection stems from the incompetent immune response to $\mathrm{HBV}$ which results in low-level liver cell destruction and regeneration over long periods of time and ultimately leads to fibrosis, cirrhosis, steatosis, and eventually HCC [24]. It is increasingly apparent that genetic factors including gene polymorphisms play a grave role in determining the risk of $\operatorname{HBV}[1,18]$.

In conclusion, our study demonstrated that PTEN 32-bp Ins/Del (rs34421660) as well as TP53 16-bp Ins/ Del genetic polymorphisms were not associated with the susceptibility to HBV in this Iranian population. To the best of our knowledge, this is the first study to examine the impact of two Ins/Del variations in PTEN and TP53 genes on predisposition to $\mathrm{CHB}$ infection. However, there are some limitations to this study which are the small sample size of the study that may affect the statistical power. Further populations with large sample sizes need to be studied to verify the exact role of PTEN and TP53 polymorphisms in hepatitis $B$. The other limitation is lacking the information for albumin-bilirubin score as an important factor for analyzing long term prognosis of HBV patients.

Acknowledgements The authors are grateful for the cooperation of all individuals who voluntarily took part in the present study. We thank the Research Deputy of Zahedan University of Medical Sciences, Iran for funding this research.

\section{References}

1. Abbott W, et al. Polymorphism in intron 1 of the interferongamma gene influences both serum immunoglobulin E levels and the risk for chronic hepatitis B virus infection in Polynesians. Immunogenetics. 2007;59(3):187-95.

2. Bao W, et al. Loss of nuclear PTEN in HCV-infected human hepatocytes. Infect Agent Cancer. 2014;9:23.

3. Birerdinc A, et al. Gene expression profiles associated with anaemia and ITPA genotypes in patients with chronic hepatitis $\mathrm{C}$ (CH-C). J Viral Hepat. 2012;19(6):414-22.

4. Chang MH. Hepatitis B virus infection. Semin Fetal Neonatal Med. 2007;12(3):160-7.

5. Chung TW, et al. Hepatitis B Virus $X$ protein modulates the expression of PTEN by inhibiting the function of p53, a transcriptional activator in liver cells. Cancer Res. 2003;63(13):3453-8.

6. Chung TW, Lee YC, Kim CH. Hepatitis B viral HBx induces matrix metalloproteinase-9 gene expression through activation of ERK and PI-3K/AKT pathways: involvement of invasive potential. FASEB J. 2004;18(10):1123-5.

7. de Andrade DR Jr, de Andrade DR. The influence of the human genome on chronic viral hepatitis outcome. Rev Inst Med Trop Sao Paulo. 2004;46(3):119-26.

8. Dienstag JL. Hepatitis B virus infection. N Engl J Med. 2008;359(14):1486-500. 
9. Ding J, et al. Association of PTEN polymorphisms with susceptibility to hepatocellular carcinoma in a Han Chinese population. DNA Cell Biol. 2011;30(4):229-34.

10. Du Y, et al. Phosphatase and tensin homologue genetic polymorphisms and their interactions with viral mutations on the risk of hepatocellular carcinoma. Chin Med J (Engl). 2015;128(8):1005-13.

11. Eskandari-Nasab E, et al. Effect of TP53 16-bp and beta-TrCP 9-bp INS/DEL polymorphisms in relation to risk of breast cancer. Gene. 2015;568(2):181-5.

12. Hashemi M, et al. Lack of association between paraoxonase-1 Q192R polymorphism and rheumatoid arthritis in southeast Iran. Genet Mol Res. 2010;9(1):333-9.

13. Hashemi M, et al. Association of promoter methylation and 32-bp deletion of the PTEN gene with susceptibility to metabolic syndrome. Mol Med Rep. 2013;7(1):342-6.

14. Hashemi M, et al. Association between polymorphisms in TP53 and MDM2 genes and susceptibility to prostate cancer. Oncol Lett. 2017;13(4):2483-9.

15. Horie Y, et al. Hepatocyte-specific Pten deficiency results in steatohepatitis and hepatocellular carcinomas. J Clin Invest. 2004;113(12):1774-83.

16. $\mathrm{Hu} \mathrm{S}$, et al. The association between polymorphism of P53 codon $72 \mathrm{Arg} /$ Pro and hepatocellular carcinoma susceptibility: evidence from a meta-analysis of 15 studies with 3704 cases. Meta Gene. 2013;1:126-37.

17. Kang-Park S, et al. PTEN modulates hepatitis B virus-X protein induced survival signaling in Chang liver cells. Virus Res. 2006;122(1-2):53-60.

18. Laaribi $\mathrm{AB}$, et al. Association of an HLA-G 14-bp Insertion/ Deletion polymorphism with high HBV replication in chronic hepatitis. J Viral Hepat. 2015;22(10):835-41.

19. Lai CL, et al. Viral hepatitis B. Lancet. 2003;362(9401):2089-94.

20. Lebok P, et al. Partial PTEN deletion is linked to poor prognosis in breast cancer. BMC Cancer. 2015; 15:963.
21. Li HG, et al. Association of PTEN gene polymorphisms with liver cancer risk. Int J Clin Exp Pathol. 2015;8(11):15198-203.

22. Lok AS, McMahon BJ. Chronic hepatitis B. Hepatology. 2007;45(2):507-39.

23. Mah YH, et al. Serum p53 gene polymorphisms and severity of hepatitis B or C-related chronic liver diseases in Taiwan. Hepatol Int. 2011;5(3):814-21.

24. Matsuda S, Kobayashi M, Kitagishi Y. Roles for PI3K/AKT/ PTEN pathway in cell signaling of nonalcoholic fatty liver disease. ISRN Endocrinol. 2013;2013:472432.

25. Peyrou M, Bourgoin L, Foti M. PTEN in liver diseases and cancer. World J Gastroenterol. 2010;16(37):4627-33.

26. Peyrou M, Bourgoin L, Foti M. PTEN in non-alcoholic fatty liver disease/non-alcoholic steatohepatitis and cancer. Dig Dis. 2010;28(1):236-46.

27. Shearn CT, et al. Increased carbonylation of the lipid phosphatase PTEN contributes to Akt2 activation in a murine model of early alcohol-induced steatosis. Free Radic Biol Med. 2013;65:680-92.

28. Steck PA, et al. Identification of a candidate tumour suppressor gene, MMAC1, at chromosome 10q23.3 that is mutated in multiple advanced cancers. Nat Genet. 1997;15(4):356-62.

29. Szpakowski JL, Tucker LY. Causes of death in patients with hepatitis B: a natural history cohort study in the United States. Hepatology. 2013;58(1):21-30.

30. Wang L, et al. Epigenetic and genetic alterations of PTEN in hepatocellular carcinoma. Hepatol Res. 2007;37(5):389-96.

31. Zampino R, et al. Hepatitis B virus burden in developing countries. World J Gastroenterol. 2015;21(42):11941-53.

32. Zhang TC, et al. A meta-analysis of the relation of polymorphism at sites -1082 and -592 of the IL-10 gene promoter with susceptibility and clearance to persistent hepatitis B virus infection in the Chinese population. Infection. 2011;39(1):21-7. 